\title{
Granulomatous cholecystitis in a patient with schistosoma mansoni infection: A case report
}

\author{
Konstantinos Manes, Kleantis Chatzimargaritis, Dimitra Apessou, \\ Vasileios Papastergiou, Christos Dervenis
}

\begin{abstract}
Introduction: Schistosomal cholecystitis is remarkably uncommon. Almost all of the reported cases in literature, less than eleven universally, are associated with concomitant gallstone disease. It is unclear whether the extensive fibrocalcific reaction of the bladder's wall and the cystic duct, seen in all cases, predisposes to cholelithiasis, or gallstones coexist. Case report: We report a Greek patient who developed schistosomal granulomatous lithiasic cholecystitis, which is unique in Greek medical chronicles. Performing a safe cholecystectomy in this patient was extremely difficult due to badly inflamed gallbladder. Conclusion: Schistosoma infection is associated with chronic granulomatous inflammation making cholecystectomy difficult and unsafe. In this article, we focus especially on prevention of bile duct injury by being prepared that a patient with a possible schistosomal cholecystitis will present with a complicated case.
\end{abstract}

Konstantinos Manes ${ }^{1}$, Kleantis Chatzimargaritis ${ }^{2}$, Dimitra Apessou $^{3}$, Vasileios Papastergiou ${ }^{4}$, Christos Dervenis ${ }^{5}$ Affiliations: ${ }^{1}$ Consultant General Surgeon, Surgical Department, "Konstantopouleio" General Hospital, Athens, Greece; 'Resident in General Surgery, Surgical Department, "Konstantopouleio" General Hospital, Athens, Greece; "Director, Pathology Department, "Konstantopouleio" General Hospital, Athens, Greece; ${ }^{4}$ Resident, Gastroenterology Department, "Konstantopouleio" General Hospital, Athens, Greece; 5Head of Surgical Department, Konstantopouleio" General Hospital, Athens, Greece.

Corresponding Author: Konstantinos Manes, Surgical Department, "Konstantopouleio" (Agia Olga) General Hospital, 14233, Athens, Greece; Ph: +30 213 2057539; Fax: +30 2132057541; Email: dinos_manes@yahoo.com

Received: 26 March 2014

Accepted: 14 April 2014

Published: 01 June 2014
Keywords: Cholecystitis, Schistosomal cholecystitis, Schistosomiasis, Parasites

\section{How to cite this article}

Manes K, Chatzimargaritis K, Apessou D, Papastergiou V, Dervenis C. Granulomatous cholecystitis in a patient with schistosoma mansoni infection: A case report. International Journal of Case Reports and Images 2014;5(6):439-443.

doi:10.5348/ijcri-201484-CR-10395

\section{INTRODUCTION}

Schistosomiasis is a parasitic disease caused by a trematode helminth of the schistosoma genus, acquired by contact with contaminated water [1]. Nowadays, schistosomiasis remains a major public health problem which affects approximately 200 million people worldwide [2]. As acquisition of the infection is linked with poor socioeconomic and sanitary conditions, the burden of the disease is higher in developing countries, particularly in sub-Saharian Africa, where prevalence of the infection is highly endemic. There are five main species of schistosoma accounting for human infestation: S. mansoni, S. haematobium, S. japonicum, $S$. intercalatum and $S$. mekongi [2]. Gastrointestinal manifestations, mainly caused by deposition of $S$. mansoni eggs in the gut wall, are the most common. Indeed, 1-2\% of appendectomy specimens have been reported to contain schistosomes in endemic areas [3]. Hepatosplenic schistosomiasis is the most severe form, representing a common cause of non-cirrhotic portal hypertension, associated with a significant mortality [4].

Herein, we present a rare case of granulomatous cholecystitis associated with deposition of $S$. mansoni eggs in the gallbladder of a 77 years old male with concomitant cholelithiasis. Infection was acquired by drinking contaminated water. The patient did not 
present any hepatosplenic or urinary manifestation. Moreover, we provide a comprehensive overview of the available literature relevant to the topic of schistosomal cholecystitis.

\section{CASE REPORT}

A 77-year-old male, born in Greece who had settled for 25 years in Zaire, was presented to our department for selective cholecystectomy. Three months before the patient was admitted in another hospital with acute lithiasic cholecystitis. The therapeutic plan at that time constituted of conservative treatment, with intravenous antibiotics for a period of one week, and delayed cholecystectomy.

On presentation to our department the patient reported a history of dull abdominal pain originating in the right upper quadrant together with repeated episodes of nausea and vomiting, lasting the past three months. Physical examination, on admission, revealed tenderness in the right upper quadrant and a +/- Murphy sign, whereas there was no palpable mass. Laboratory tests showed normal white blood cells count with only a mild increase in $\gamma$-glutamyl transpeptidase $(88 \mathrm{IU} / \mathrm{mL})$ and alkaline phosphatase (145 IU/mL) levels. The patient kept afebrile the whole period. Upper abdominal ultrasound was performed, showing a 1.7-cm gallstone impacted in the neck of a thick-walled (6.8 mm) gallbladder (Figure 1).

The imaging finding of gallbladder's wall thickening was suggestive of acute inflammation (>4 $\mathrm{mm}$ according to the last Tokyo Guidelines 2013 concerning the management of acute cholecystitis) [5]. But, since there were no clinical-laboratory signs of acute exacerbation of the disease (no fever nor leukocytosis), it was decided to proceed to selective cholecystectomy.

When laparascopy was performed, the gallbladder appeared grey with very thick wall. Retraction of the gall bladder with a grasper and mobilization was impossible due to the impacted stone in bladder's neck and the strong adhesions to the hepatoduodenal ligament. A safe laparoscopic procedure could not be obtained, since the "critical view of safety" exposure technique for Calot's triangle could not be achieved [6]. Apart from this, the gallbladder being firmly adherent to the liver bed was giving the impression that it was actually infiltrating it. Given the suspicion of cancer and being unable to perform a safe technique, conversion to open approach was considered.

On laparotomy, the gallbladder's wall appeared extremely inflamed and thick with necrotic spots and wood-like consistence (Figure 2). Mobilization was really hard to accomplish. A retrograde approach was decided and primarily the dome of the gallbladder was removed. After draining the content the impacted stone was extracted. This approach allowed safe identification and ligation of the cystic duct and artery and finally the gallbladder was safely excised.
Histopathological examination showed marked granulomatous inflammation surrounding numerous calcified parasite eggs suggestive of $S$. mansoni. Remarkable fibrocalcific changes were noted in both the gallbladder and cystic duct walls (Figures 3 and 4).

Postoperatively, the patient's abdominal pain improved and the laboratory tests normalized. He received praziquantel $20 \mathrm{mg} / \mathrm{kg}$ orally every 4 hours for 3 doses. After 6 months of follow-up the patient remains asymptomatic.

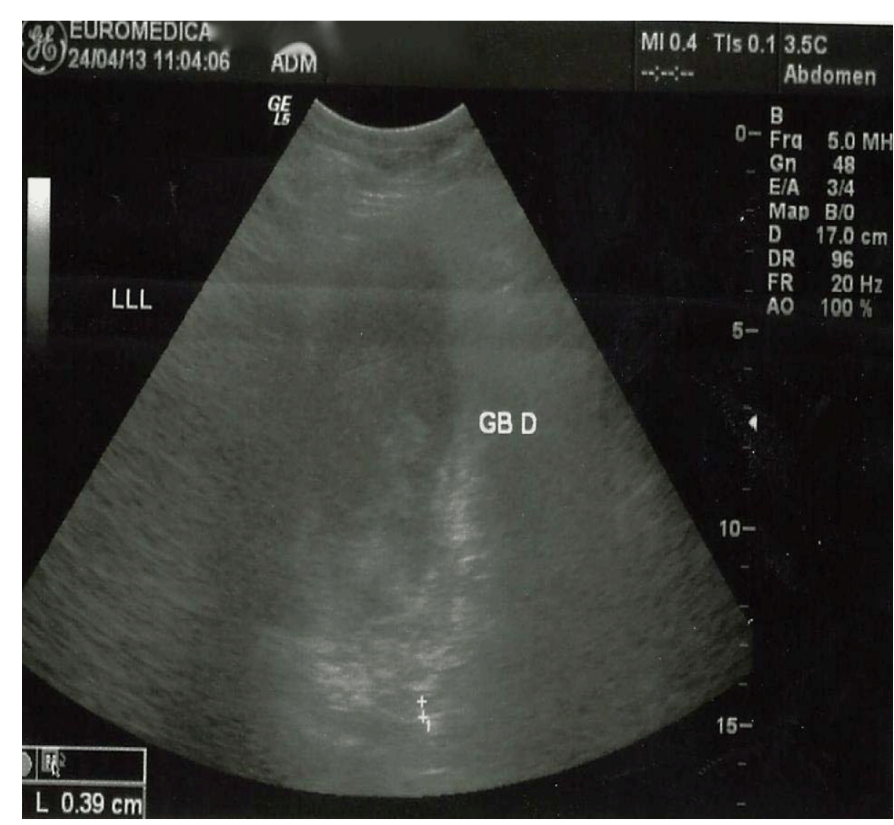

Figure 1: Ultrasound showing a contracted gallbladder with marked, diffuse thickening of the bladder's wall and impacted stone at the neck.

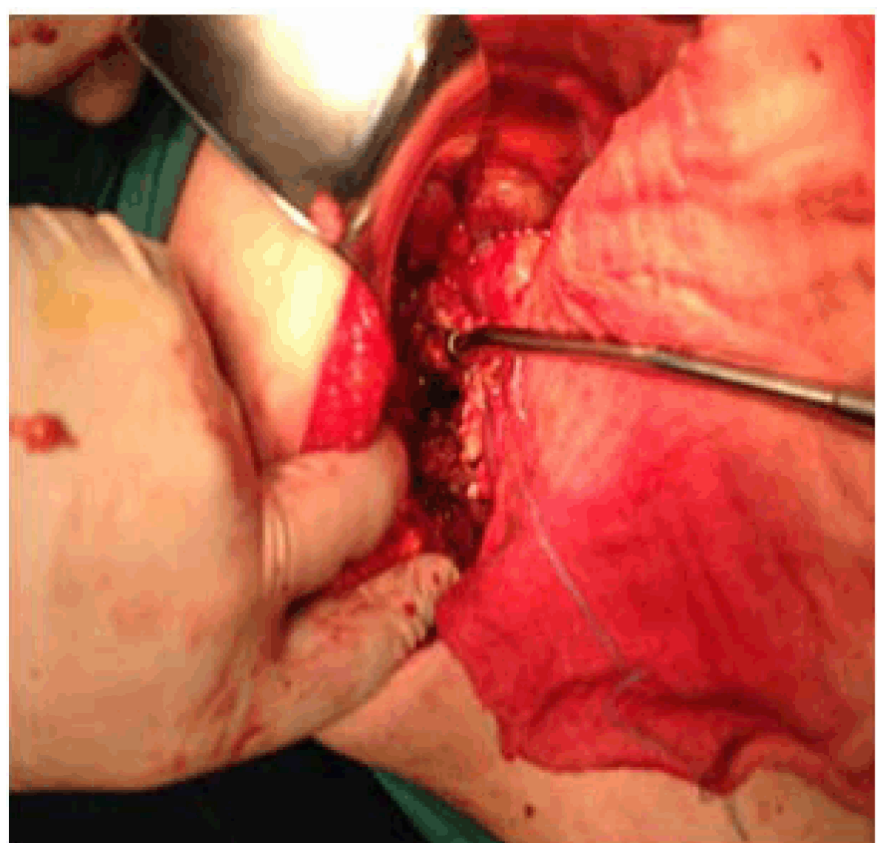

Figure 2: Gallbladder's wall extremely inflamed and thick with extensive fibrotic granulomatous reaction, as shown on laparotomy. 


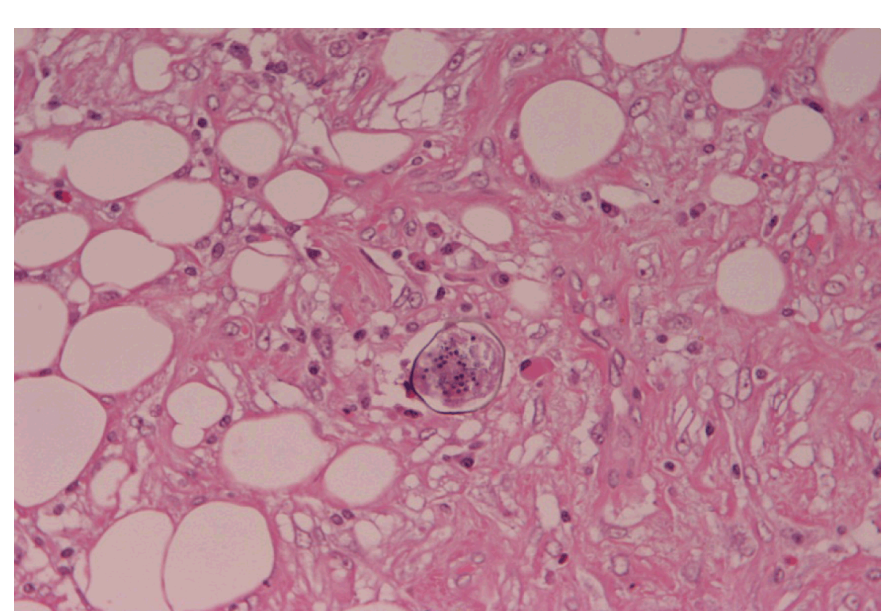

Figure 3: High magnification of a schistosomal ovum surrounded by histiocytes and necrotic debris, with its characteristic brown colored outer layer (H\&E stain, x400).

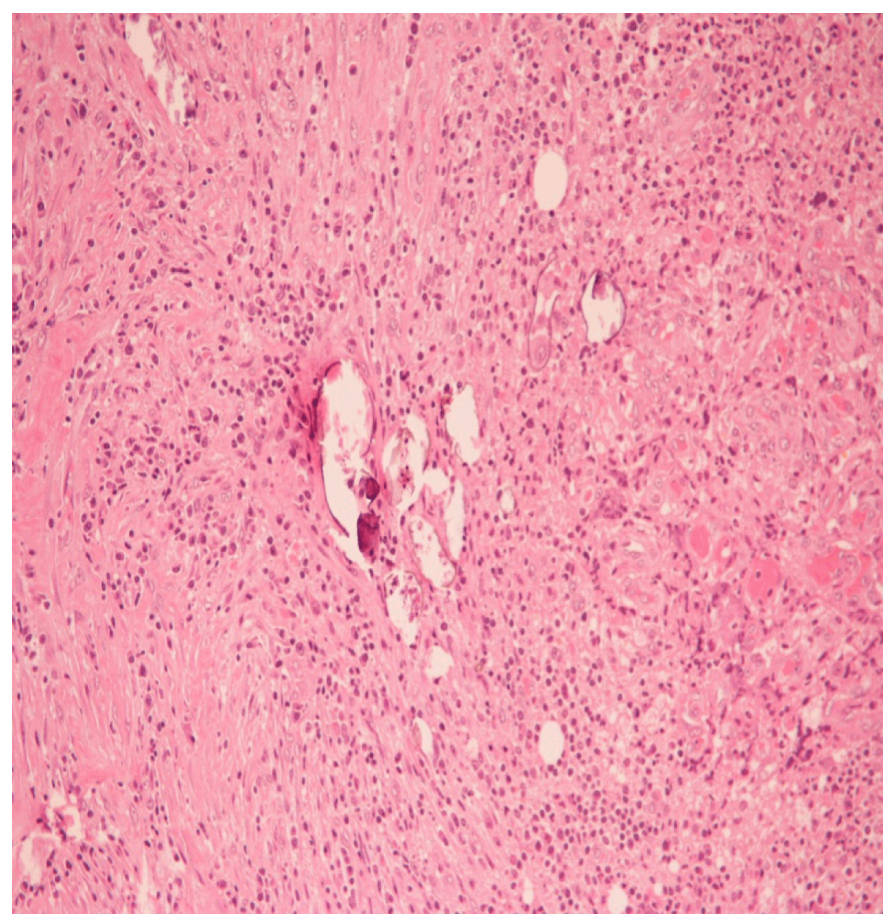

Figure 4: Fibrocalcified parasite and scattered ova inside necrotizing granuloma (H\&E stain, x200).

\section{DISCUSSION}

Chronic schistosomiasis is the result of the host's immune response to schistosomal eggs inducing the development of delayed-type hypersensitivity granulomas [7]. As schistosomal eggs can be found in any tissue, schistosomiasis is a systemic disease. Although ultrasonographic abnormalities are prevalent in the gallbladder of patients with hepatosplenic schistosomiasis, including calcification and thickening of the wall with reduced fasting volume [8], a granulomatous cholecystitis with schistosomal egg deposition is an uncommon histopathological finding with few reports in the international literature. Notably, a variety of other conditions including Crohn's disease, X-linked chronic granulomatous disease, fibroelastosis of the gallbladder and xanthogranulomatous cholecystitis, as well as infection with Mycobacterium Tuberculosis and Candida glabrata may account for granulomatous cholecystitis [9-12]. As $S$. mansoni is not endemic in Greece, it is reasonable to assume that our patient has been infected during his long permanence in Zaire, a country highly endemic for schistosomiasis mansoni [13]. Overall, a total of eleven cases of schistosomal cholecystitis have been described in the medical literature, in five articles published between 1975 and 2009 [14-18]. However, a direct causal link between deposition of schistosomal ova and development of symptomatic cholecystitis remains questionable. Indeed, in 9 out of the 11 cases, concurrent presence of cholelithiasis (which is by far the most common cause of cholecystitis universally) was reported, as in our case. Congruently with previous reports, we found intense fibrocalcific reaction accompanying the chronic schistosoma-induced granulomatous inflammation. To explain the apparent association between gallbladder schistosomiasis and cholelithiasis, $\mathrm{Al}-\mathrm{Saleem}$ et al. have postulated that fibrotic stenosis of the cystic duct may contribute to the stagnation of bile in the gallbladder and thus to the formation of gallstones [15]. In contrast, evidence of a direct involvement of schistosoma on triggering an acute cholecystitis has been provided by Sharara et al. Indeed, these authors reported a case of alithiasic schistosomal cholecystitis in which no gallbladder abnormalities were ecographically demonstrable 10 days prior to the initiation of symptoms [18]. In a single case, schistosomal cholecystitis has been described along with adenocarcinoma of the gallbladder [14]. However, this was probably an incidental finding as no evidence has been provided as yet to support such an association. Notably, apart from S. mansoni, also $S$. haematobium may account for schistosomal cholecystitis [15].

In summary, it remains inconclusive whether deposition of schistosomal eggs in the gallbladder may trigger "per se" an episode of acute cholecystitis. However, in the light of increasing reports of schistosomal infection along with cholelithiasis (as in this case), a lithogenic effect of schistosomiasis secondary to the induction of chronic granulomatous and fibrocalcific changes of the gallbladder and biliary ducts wall, seems undeniable.

\section{CONCLUSION}

Schistosoma infection is associated with chronic granulomatous inflammation making cholecystectomy difficult and unsafe. Physicians should bear in mind the possibility of an acute biliary episode as a rare complication of infection with $S$. mansoni. This is especially important for surgeons practicing in highly endemic settings or patients with a travel history or exposure in these endemic 
areas, as it is difficult to perform a safe cholecystectomy in these cases, even through an open approach.

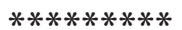

\section{Author Contributions}

Konstantinos Manes - Conception and design, Acquisition of data, Analysis and interpretation of data, Drafting the article, Critical revision of the article, Final approval of the version to be published

Kleantis Chatzimargaritis - Acquisition of data, Drafting the article, Final approval of the version to be published Dimitra Apessou - Analysis and interpretation of data, Critical revision of the article, Final approval of the version to be published

Vasileios Papastergiou - Acquisition of data, Analysis and interpretation of data, Drafting the article, Critical revision of the article, Final approval of the version to be published

Christos Dervenis - Conception and design, Critical revision of the article, Final approval of the version to be published

\section{Guarantor}

The corresponding author is the guarantor of submission.

\section{Conflict of Interest}

Authors declare no conflict of interest.

\section{Copyright}

(C) 2014 Konstantinos Manes et al. This article is distributed under the terms of Creative Commons Attribution License which permits unrestricted use, distribution and reproduction in any medium provided the original author(s) and original publisher are properly credited. Please see the copyright policy on the journal website for more information.

\section{REFERENCES}

1. Gryseels B, Polman K, Clerinx J, Kestens L. Human schistosomiasis. Lancet 2006;368(9541):1106-18.

2. Gryseels B. Schistosomiasis. Infect Dis Clin North Am 2012;26(2):383-97.

3. Satti MB, Tamimi DM, Al Sohaibani MO, Al Quorain A. Appendicular schistosomiasis: A cause of clinical acute appendicitis? J Clin Pathol 1987;40(4):424-8.

4. Andersson KL, Chung RT. Hepatic schistosomiasis. Curr Treat Options Gastroenterol 2007;10(6):50412.

5. Yamashita Y, Takada T, Strasberg SM, et al. TG13 Surgical management of acute cholecystitis. J Hepatobiliary Pancreat Sci 2013 Jan;20(1):89-6.

6. Strasberg SM, Hertl M, Soper NJ. An analysis of the problem of biliary injury during laparoscopic cholecystectomy. J Am Coll Surg 1995 Jan;180(1):101-25.
7. Warren KS. Hepatosplenic schistosomiasis mansoni: An immunologic disease. Bull N Y Acad Med 1975;51(4):545-50.

8. Ali QM, Abdel-Rahim IM, Doehring-Schwertfegar $\mathrm{E}$, et al. Ultrasonographic evaluation of gallbladder function in patients with Schistosoma mansoni infection. Trop Doct 1990;20(3):113-5.

9. Andoh A, Endo Y, Kushima R, et al. A case of Crohn's disease involving the gallbladder. World J Gastroenterol 2006;12(6):977-8.

10. Evert M, Roessner A, Rocken C. Synchronous granulomatous cholecystitis and fibroelastosis of the gallbladder. Virchows Arch 2004;445(6):655-8.

11. Rojo P, Ruiz-Contreras J, Gonzalez-Tome M, Serrano C, Marin MA. Outpatient treatment with corticosteroids and antibiotics for acalculous cholecystitis in chronicgranulomatous disease. Acta Paediatr 2005;94(11):1684-6.

12. Spinelli A, Schumacher G, Pascher A, et al. Extended surgical resection for xanthogranulomatous cholecystitis mimicking advanced gallbladder carcinoma: A case report andreview of literature. World J Gastroenterol 2006;12(14):2293-6.

13. Polderman AM, de Caluwe P. Eight years of targeted mass treatment of Schistosoma mansoni infection in Maniema, Zaire. Trop Med Parasitol 1989;40(2):177-80.

14. Alam K, Maheshwari V, Jain A, et al. Schistosomiasis: A cases series, with review of literature. The Internet Journal of Infectious Diseases 2009;7.

15. Al-Saleem T, Al-Janabi T. Schistosomal cholecystitis: Report of six cases. Ann R Coll Surg Engl 1989;71(6):366-7.

16. Marcial MA, Marcial-Rojas RA. Cholecystitis due to Schistosoma mansoni, fact or fancy. Bol Asoc Med P R 1989;81(5):178-9.

17. Rappaport I, Albukerk J, Schneider IJ. Schistosomal cholecystitis. Arch Pathol 1975;99(4):227-8.

18. Sharara AI, Abi-Saad G, Haddad M, Mansour A, Tawil A. Acute granulomatous schistosomal cholecystitis. Eur J Gastroenterol Hepatol 2001;13(8):1001-3. 
Access full text article on other devices

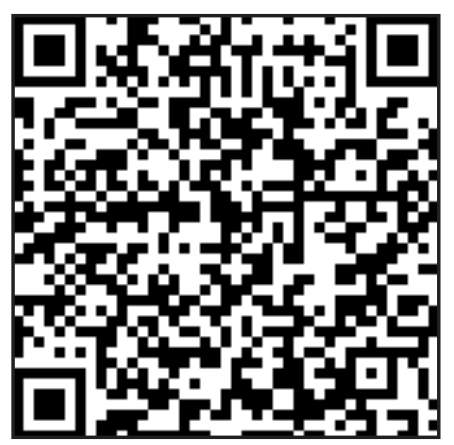

Access PDF of article on other devices

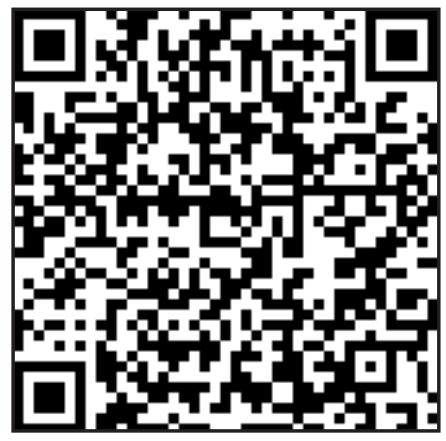

